\title{
Evaluation Index System of E-commerce Talents Based on AHP
}

\section{Xiaowei Zhu ${ }^{1,2}$ and Qi Lu}

\author{
${ }^{1}$ Wuhan Technology and Business University, China, HuBei, Wuhan, 430065 \\ ${ }^{2}$ Hubei Business Service Development Research Center, China, HuBei, Wuhan, 430065
}

Keywords: Analytic hierarchy process; E-Commerce; Skills; Evaluation

\begin{abstract}
This is an information technology era, in which e-commerce industry will have a rapid development. So the requirements of relevant talents will be more strict, which requires a perfect e-commerce skills evaluation system to select excellent e-commerce talents for society. In order to adapt to the development of the times, we can establish the analytic hierarchy process (AHP) to manage the e-commerce market more perfectly and standardly, determine the weights of e-commerce talent's skills, and divide this complex e-commerce system into several levels and objectives to make the evaluation on e-commerce talent's skills more clearly.
\end{abstract}

\section{Skill Requirements for E-Commerce Talents}

\section{Professional Skill Required for E-commerce Talents}

Study of Fundamental Theories of Economic Management and Relevant Laws and Regulations

E-commerce talents should master the fundamental theories and skills of Economics and Management. And through studying the main courses of e-commerce, they can possess and master certain relevant theories and skills. Hence, in the later study and word, they can use these theories and skills to solve some problems in practical operation.

The Ability of E-commerce Project Planning and Operations Management

E-commerce talents should have the certain ability of project planning and the corresponding ability of operations management and know the operational process of e-commerce project through studying the relevant professional knowledge. They should have a good communication skill to know the demand of customer and make an appropriate plan and at the same time, they also should know certain skills of network marketing and have the ability to collect, filter and edit the information and operate and manage the project according to the plan.

The ability of Building and Managing E-commerce Websites

E-commerce talents should study the principles of computer network and apply these theories to the work to solve the relevant problems they will meet in constructing and managing e-commerce. In order to do the other relevant jobs of e-commerce better, e-commerce talents should not only study the relevant courses of the design of e-commerce website but also design dynamic website independently and they also should study and master the relevant skills of website promotion.

The Ability of Developing and Promoting Internet Products

E-commerce talents should possess good capability for developing and managing Internet products for their jobs rely greatly on Internet. They should learn and be equipped with relevant theories. They need to carry out certain project planning before starting product development and then conduct analysis and design to finally release the corresponding product and also operate and promote it online according to the product features.

\section{Indicator of Skill Assessment System for E-Commerce People}

\section{Method Used by Index System: Analytic Hierarchy Process (AHP)}

\section{Definition}

In the analytic hierarchy process, it is to classify decision-making problems into different hierarchical structures in the order of general objective, sub-objectives in hierarchies, assessment rule and specific backup scheme, then use the method of solving the eigenvector of judgment vector to obtain the priority weight of element in each hierarchy corresponding to an element in upper 
hierarchy and apply the weighted sum at last to hierarchically merge the final weight of backup scheme against the general objective. The largest final weight is the optimal plan ${ }^{[3]}$.

\section{Basic Steps}

Construction of Hierarchical Structure Model

In solving realistic problems, we need to have deep thoughts and analysis at first and then classify each indicator into several hierarchies according to indicators' dissimilar characteristics, where indicator in each hierarchy should keep subordinating relation with or can interfere with the indicator of the upper hierarchy. Generally, the top hierarchy of hierarchical structure model is called objectives level which controls the overall structure through only one indicator. The scheme level is the bottom level because it concerns the specific operation steps. The intermediate level is usually referred to as criterion level and does not need to be an unique level. If the number of indicators is too large, indicators can be classified.

Construction of Pairwise Comparison Matrix

From the criterion level of AHP model to the scheme level, indicators in criterion level, who subordinates to or interfere with indicators in objectives level, are to construct the pairwise comparison matrix with pairwise comparison method and $1-9$ comparison scales.

Construction of Judgment Matrix

One of essential characteristics of the analytic hierarchy process is the 2-2 ratio importance which is a form of relative importance in two schemes. The judgment matrix has the following features: and $/(=1,2, \ldots)$, indicating they are reciprocal matrices.

Table1 Table of ratio scale

\begin{tabular}{|c|c|}
\hline $\begin{array}{c}\text { Comparison of Two Factors } \\
\text { Two factors compared with } \\
\text { the same importance }\end{array}$ & Quantitative Values \\
\hline $\begin{array}{c}\text { A factor is slightly } \\
\text { important than the other one }\end{array}$ & 3 \\
\hline $\begin{array}{c}\text { A factor is obviously } \\
\text { important than the other one }\end{array}$ & 5 \\
\hline $\begin{array}{c}\text { A factor is strongly } \\
\text { important than the other }\end{array}$ & 7 \\
\hline $\begin{array}{c}\text { A factor is extremely } \\
\text { important than the other }\end{array}$ & 9 \\
\hline $\begin{array}{c}\text { The median in the two } \\
\text { adjacent judgments }\end{array}$ & $2,4,6,8$ \\
\hline
\end{tabular}

\section{Calculation of Weight Vector}

Definition: if...is established, we will say the judgment matrix satisfies the consistency and we call it consistent matrix. We can use the required judgment matrix to obtain the corresponding eigenvectors which will be the weights after being normalized. If there is no consistency in the judgment matrix, the weights we obtain will have errors.

Consistency Check

If the order of judgment matrix is too large, it is not easy to obtain a consistent matrix. But, when the judgment matrix is not consistent, it has a reasonable range which means it should receive a consistency check. The smaller the $\mathrm{CI}$ is, the larger the consistency is. When the CR $<0.1$ means the judgment matrix has the feature of consistency, otherwise, it would not consistent. The corresponding relationship of random consistency indicator of RI is shown in Fig. 2. 
Table 2 Standard mean value of random consistency indicator RI (The RI value will have little differences because of different standards)

\begin{tabular}{|l|l|l|l|l|l|l|l|l|l|l|}
\hline $\begin{array}{l}\text { Matrix } \\
\text { order }\end{array}$ & 1 & 2 & 3 & 4 & 5 & 6 & 7 & 8 & 9 & 10 \\
\hline RI & 0 & 0 & 0.58 & 0.90 & 1.12 & 1.24 & 1.32 & 1.41 & 1.45 & 1.49 \\
\hline
\end{tabular}

From this table, the analytic hierarchy process is not only easy to understand, but also has a strict theoretical basis, which is a significant decision-making method combined of qualitative and quantitative methods, especially referring to the condition when the qualitative indicator leads the decision.

\section{Evaluation Index System of E-commerce Talents Skills}

The Selection of Evaluation Index. Based on the analysis of skill requirement of e-commerce talents, in order to make a comprehensive evaluation of e-commerce talents skills, we put forward a quality structure index system which includes the study of basic theory of economics and management and the relevant laws and regulations, the ability of project planning and operational management, the ability of the construction and management of e-commerce website and the ability of developing and promoting internet product.

Table 3 "Study of basic theory of economics and management- mastery of the relevant laws and regulations- ability of Internet marketing and logistics management- master the principle and application of computer network- ability of the construction and management of e-commerce website" structure assessment indicator system (hereinafter referred to as"TLMIW"system)

\begin{tabular}{|c|c|}
\hline Assessment Program(weight) & Assessment Indicator(sub-weight) \\
\hline \multirow{3}{*}{$\begin{array}{l}\text { T study of basic theory of economics and } \\
\text { management and the relevant laws and } \\
\text { regulations }(0.20)\end{array}$} & T1 basic theory of economics $(0.32)$ \\
\hline & T2 basic theory of management $(0.56)$ \\
\hline & $\mathrm{T} 3$ relevant laws and regulations $(0.12)$ \\
\hline \multirow{4}{*}{$\begin{array}{l}\text { M ability of project planning and } \\
\text { operational management }(0.25)\end{array}$} & M1 ability of project planning $(0.54)$ \\
\hline & M2 high communication ability $(0.07)$ \\
\hline & $\begin{array}{c}\text { M3 ability of project operational } \\
\text { management }(0.24)\end{array}$ \\
\hline & M4 demand analysis ability $(0.15)$ \\
\hline \multirow{3}{*}{$\begin{array}{c}\text { I ability of the construction and } \\
\text { management of e-commerce website } \\
(0.30)\end{array}$} & $\begin{array}{l}\text { I1 ability of multimedia technology and } \\
\text { picture processing }(0.11)\end{array}$ \\
\hline & $\begin{array}{l}\text { I2 ability of network operation and } \\
\text { management of e-commerce }(0.26)\end{array}$ \\
\hline & $\begin{array}{c}\text { I3 ability of designing } \\
\text { e-commerce }(0.63)\end{array}$ \\
\hline \multirow[t]{4}{*}{$\begin{array}{l}\text { W ability of developing and promoting } \\
\text { internet product }(0.25)\end{array}$} & $\begin{array}{l}\text { W1 product development and publishing } \\
\text { ability }(0.22)\end{array}$ \\
\hline & W2 team cooperation ability $(0.05)$ \\
\hline & $\begin{array}{l}\text { W3 ability of product design planning } \\
\text { and promotion }(0.58)\end{array}$ \\
\hline & $\begin{array}{l}\text { W4 ability of system operation and } \\
\text { maintenance }(0.15)\end{array}$ \\
\hline
\end{tabular}

Take the table 3 as a example, according to the skill requirement of e-commerce talents, the study of basic theory of economics and management and the relevant laws and regulations is consisted of assessment indicator of basic theory of economics, basic theory of management and 
relevant laws and regulations; the structure of the ability of project planning and operational management is consisted of assessment indicator of ability of project planning, high communication ability, ability of project operational management and demand analysis ability; the structure of ability of the construction and management of e-commerce website is consisted of assessment indicator of ability of multimedia technology and picture processing, ability of network operation and management of e-commerce and ability of designing e-commerce; the structure of ability of developing and promoting internet product is consisted of assessment indicator of product development and publishing ability, team cooperation ability, ability of product design planning and promotion and ability of system operation and maintenance.

The Determination of Assessment Indicator Weight. Due to the difference influence of each assessment indicator of e-commerce talents' skills, the weight of indicator are also different which means each indicator should have different weight. Considering the features of e-commerce talents, the assessment team is consisting of senior e-commerce operator, HR manager, colleagues of employees to be assessed and some subordinate staff of immediate sector, in order to determine the weight of each indicator.

The determination of Each Assessment Item Weight and Its Assessment Indicator Weight

Considering a certain indicator as an object of reference, we use the relative weight to obtain his proportion in the whole indicator; since we want to evaluate the e-commerce talents, but the importance of above said factors to the assessment of e-commerce talents' skills cannot be objectively quantified, and a great deal of them need to be quantified a lot of times with many subjective factors of each relative weight. So, we choose "fuzzy mathematical model analysis" and "Delphi Method" to obtain the whole sub-weights of e-commerce talents' skills assessment.

\section{Taking skills of electronic information industry talents as an example to conduct the assessment and analysis}

Table 3 indicates the skills assessment indicator system of E-commerce talents according to the above-mentioned procedures (the weight coefficient is added to indicator system), we would select talents from electronic information industry to conduct the skills assessment indicator to demonstrate the reasonability of this assessment indicator system.

Preparing and Distributing E-commerce Talents Skills Assessment Grading Evaluation List. For the purpose of convenience, we firstly represent each assessment factor with its English name's first letter in upper case, and each assessment factor is represented in the form of English letter of its belonging assessment item and number, which are listed in table 3 . We devide all kinds of assessment factors into the following four levels: excellent, good, fair and failed, and represent them with $M$. So we could get that $M=\{M 1, M 2, M 3, M 4\}$ equals to \{excellent, good, fair, failed and an assessment table like table 9.

Handing out the table 9 to each member in the assessment group and let he or she fills the table based on the reality, group members assess which level should the specific factor of each E-commerce talent be assigned to according to their judgment, then mark " $\sqrt{ }$ " at the appropriate partition in table, note that each assessment factor could only choose one level.

Gathering and Making E-commerce Talents Skills Assessment Grading Evaluation Statistical List. Gather grading evaluation list from each member in the assessment group and make a statistic, then record the number of appearance of each level's number of people in corresponding level, which could get each assessment factor's grading evaluation statistical list, this time, we only list one of electronic information industry talent's skills assessment grading evaluation result from group at table 10 .

Certain assessment factor is assessed as certain proportion at certain level $=$ number of members who assess this level / general number assessment group

We choose ten people to establish assessment group, who are two senior e-commerce specialists, two ministers of human resource, two assessed employees' colleagues, two subordinates from governed department and two assessed employees' leaders; then we would let them evaluate every 
evaluation factor of electronic information industry talent's skills and record the evaluation results in table 10, thereby get single factor evaluation analytic list of each evaluation factor.

Getting Comprehensive Evaluation Matrix of E-commerce Talents Skills Evaluation Factors. We can use single factor evaluation analytical list of each evaluation factor gained by above-mentioned method and weight set of each evaluation factor to get comprehensive evaluation matrix of each evaluation factors by the means of fuzzy mapping, which could be represented with $\mathrm{H}:$

$$
H_{T}=W_{T}{ }^{\circ} T=\left(\begin{array}{lll}
0.35, & 0.34, & 0.31
\end{array}\right)^{\circ}\left(\begin{array}{rrrl}
0.6 & 0.1 & 0.2 & 0.1 \\
0.8 & 0.2 & 0 & 0 \\
0.5 & 0.1 & 0.3 & 0.1
\end{array}\right)=(0.35,0.20,0.30,0.10)
$$

Among them, "“" uses $\mathrm{M}(\wedge, \vee)$ operator, for example, the calculating process of first-line element in comprehensive evaluation matrix $H_{T}$ could be written as:

$(0.35 \wedge 0.6) \vee(0.34 \wedge 0.8) \vee(0.31 \wedge 0.5)=(0.35 \vee 0.34 \vee 0.31)=0.35$

Other elements also can be calculated with the same method, then we could respectively get corresponding comprehensive evaluation matrix of evaluation factors represented by T, L, M, I and $\mathrm{W}$ :

$H_{T}=(0.35,0.20,0.30,0.10) ; H_{M}=(0.29,0.20,0.26,0.20) ;$

$H_{I}=(0.30,0.20,0.34,0.20) ; H_{W}=(0.31,0.20,0.30,0.10)$.

Above matrix shows the assessment indicator of e-commerce talents in this industry belongs to the degree of excellent, good, medium and poor. Therefore, the comprehensive evaluation matrix related to each evaluation factor forms the comprehensive assessment matrix of evaluation factor, referring to $\mathrm{H}$ :

$$
H=\left(\begin{array}{llll}
H_{T} & H_{M} & H_{I} & H_{W}
\end{array}\right)^{T}
$$

The weight set $\mathrm{Q}$ of evaluation factor level and its fuzzy change of comprehensive assessment matrix $\mathrm{H}$ can get the ultimate comprehensive assessment matrix, referring to $\mathrm{N}$

$$
N=\left(\begin{array}{llll}
0.20 & 0.25 & 0.30 & 0.25
\end{array}\right) \circ\left(\begin{array}{llll}
0.35 & 0.20 & 0.30 & 0.10 \\
0.29 & 0.20 & 0.26 & 0.20 \\
0.30 & 0.20 & 0.34 & 0.20 \\
0.31 & 0.20 & 0.30 & 0.10
\end{array}\right)=(0.30,0.26,0.30,0.30)
$$

Because $\mathrm{N}$ has not been normalized, which means $0.30+0.26+0.30+0.30=1.16 \neq 1$, hence, the Fuzzy Association Rules should be employed on it to normalize, each factor in $\mathrm{N}$ divides by 1.16 and obtain the ultimate comprehensive assessment matrix:

$$
N^{\prime}=\left(\frac{0.30}{1.16}, \frac{0.26}{1.16}, \frac{0.30}{1.16}, \frac{0.30}{1.16}\right)=(0.26,0.22,0.26,0.26)
$$

The Analysis of Skill Status of E-commerce Talents. Each assessment level has a corresponding number in order to express the evaluation result well. "Excellent" is 90 point, "Good" is 80 point, "Medium" is 70 point, and "Poor" is 60 point, and these method can obtain rating assignment matrix, referring to $\mathrm{P}$, e.g. $\mathrm{P}=$. Then the ultimate score of e-commerce talent skill evaluation is considered as $\mathrm{E}$, we can get:

$$
E=N^{\prime} \times M=(0.26,0.22,0.26,0.26) \times(90,80,70,60)^{T}=74.8
$$

The ultimate score of comprehensive assessment is 74.8 , which means the comprehensive skill level of e-commerce is in "Medium" level and even close to "Excellent" level. The result we got and the result of this person in annual performance assessment is almost same, since it figures out the e-commerce talent skill assessment factor system which we build is basically applicable and reasonable.

\section{Conclusion}

This paper has studied a lot about the e-commerce talent skill factors, and received a set of completed e-commerce talent skill assessment system, the analytic hierarchy process was used in 
the process of research, and we quantified the evaluation factors in each level, especially adopted some objective methods to avoid subjective influence in weighting each assessment factor, such as team evaluation and expert assessment as well as fuzzy transformation, in order to show the skill status of e-commerce talent in skill assessment objectively. Some companies can get references in choosing talents of e-commerce positions. From the skill assessment indicator system, some companies should pay attention to the learning ability of economic and management basic theory and relating laws and regulations, the ability of project planning and operation management; the ability of establishment and management of e-commerce website; and the ability of development and promotion of internet products and other abilities, from the results of the allocation of each assessment factor weight, some companies focus on the ability of program planning and operation management; the ability of e-commerce website building and management; the ability of development and promotion of internet products.

\section{Acknowledgement}

Fund Project: Hubei Provincial Collaborative Innovation Center for Modern logistics and business (Project No.2011A201307)

Fund Project: MOE (Ministry of Education in China) Project of Humanities and Social Sciences (Project No.14YJCZH154)

Funding team: Wuhan Technology and Business University Academic Team (Project No. XSTD2015004)

\section{References}

[1] Wang Ya. Research on Evaluation Method of B2C E-commerce Website Based on AHP [J]. International Proceedings of Conference.2014.68-69

[2] Qu Yunbo, Network Marketing, Beijing, Enterprise Management Publishing House, 2013. $12-14$

[3] Wang Jian, E-Commerce, Shanghai, Haitian Publishing House, 2013.16-18

[4] Ministry of Education, Research Report of China Logistics Development and Talent Demand [M]. China Goods and Materials Press (Now China Fortune Press): 2014/08. 35-37

[5] Cao Jingjing. Building of Assessment Criterion System for International Development Level of the Professional Market [J]. Statistics and Decision, 2011 (10): 73-75

[6] Yan Zheng. Manager Competency [M]. Beijing: China Machine Press, 2014.16-17

[7] Fei Donghua. Employee Computer [M].Beijing: China Economic Press, 2014.18-19

[8] Xiao Mingzheng. Personnel Quality Test. Higher Education Press, 2015.35-38

[9] Richard S Williams. Performance Mangement. London: International Thomson Business Press.2010:104

[10]Qiuwen Zhang, Ming Zhong. Using Multi-level Fuzzy Comprehensive Evaluation to Assess Reservoir Induced Seismic Risk, Journal of Computers.Vol.6.pp.1670-1676.2015

[11] Gaziel Haim Principal of Performance Assessment case study, Giusepp Omega. Vol. 94. pp. 95-103, 2013 